\title{
Comparação entre Modelos Tradicionais e Modelos Fuzzy no Estudo de Qualidade da Água do Rio Cachoeira, Região Ilhéus-Itabuna
}

\author{
Francisco B. S. Oliveira Valdex de J. Santos* ${ }^{*} \quad$ Eduardo S. Palmeira \\ Universidade Estadual de Santa Cruz \\ Programa de Pós-Graduação em Modelagem Computacional em Ciência e Tecnologia \\ 45662-900 - Rodovia Ilhéus/Itabuna, Km 16, BA, Brasil \\ E-mail: fbsoliveira@uesc.br, vjsantos@uesc.br, espalmeira@uesc.br \\ Fabio Flores Lopes \\ Universidade Estadual de Santa Cruz - Departamento de Ciências Biológicas, \\ 45662-900 - Rodovia Ilhéus/Itabuna, Km 16, BA, Brasil \\ E-mail: fabiologo5@hotmail.com
}

\section{RESUMO}

Água de boa qualidade é vital para a sobrevivência de todos os seres vivos e equilíbrio do ecossistema como um todo e, essa qualidade é definida por características físicas, químicas e biológicas. Na representação dessas características são utilizados parâmetros que servem como indicadores da qualidade da água, os quais podem ser relacionados com os tipos de fontes de poluição [6].

Os modelos mais comuns utilizados para representar o processo de classificação de corpos hídricos se denominam de modelos determinísticos [2], baseados na lógica clássica. Por conta disso têm como deficiência a incapacidade de lidar com a incerteza e a subjetividade presente nos complexos problemas ambientais. Nesse sentido, justifica-se a aplicabilidade da lógica fuzzy para tratar de problemas relacionados a qualidade da água.

O objetivo é fazer uma análise comparativa entre os modelos tradicionais de qualidade da água e o modelo baseado na lógica fuzzy, proposto neste estudo. Os modelos serão aplicados a fim de estudar a qualidade da água do rio Cachoeira que banha dois dos principais municípios da região sul da Bahia: Itabuna e Ilhéus. As simulações serão feitas com base em substâncias físico-químicas presentes na água e biológicas colhidas em peixes pescados no rio. Para tanto, serão consideradas coletas feitas entre os anos de 2012 e 2013 em seis pontos do rio Cachoeira, os quais são nomeados: P1, P2, P3, P4, P5 e P6.

O rio Cachoeira juntamente com os rios Salgado e Colônia forma a Bacia Hidrográfica do Rio Cachoeira-BHRC, a maior das bacias da região leste da Bahia [1]. Esse rio representa a síntese do que ocorre ao longo da bacia, pois todas as águas desta bacia convergem para ele, sendo assim reflete as condições ambientais da região [6]. Além de sua importância social, histórica e econômica, é fonte de subsistência de muitas famílias ribeirinhas (famílias que residem à margem do rio).

A ausência do tratamento de resíduos domésticos e seu despejo impróprio nos corpos de água têm contribuído para o agravamento dos problemas ambientais [3]. Só no município de Itabuna $90 \%$ do esgoto é lançado no rio Cachoeira sem tratamento [4]. Sendo assim, tendo em vista estes altos níveis de poluição e a grande importância desse rio para a Região Sul da Bahia, estudos sobre a qualidade de suas águas e os efeitos da poluição são necessários de forma a impulsionar políticas públicas de revitalização e recuperação.

Existem diversos modelos matemáticos que proporcionam tomadas de decisão na melhoria da qualidade da água, dentre os quais se destacam: QUAL2K, AQUATOX e WASP. Será utilizado o modelo de qualidade da água QUAL2K por ser um dos mais conhecidos, versátil e de fácil compreensão e aplicação

*Mestrando em Modelagem Computacional em Ciência e Tecnologia. 
[5]. Além disso, o modelo QUAL2K pode simular até 15 constituintes de qualidade da água e com qualquer combinação desejada pelo usuário, dentre eles: Oxigênio dissolvido (OD), Demanda Bioquímica de Oxigênio (DBO), temperatura, algas, nitrogênio orgânico, amônia, nitrito, nitrato, fósforo orgânico, fósforo dissolvido e coliformes.

O modelo QUAL2K resolve a equação básica de transporte de massa unidimensional dada por

$$
\underbrace{\frac{\partial M}{\partial t}}_{\text {Variação do constituinte }}=\underbrace{\frac{\partial\left(A_{x} D_{L} \frac{\partial C}{\partial x}\right)}{\partial x} d x}_{\text {Transporte }}-\underbrace{\frac{\partial\left(A_{x} u C\right)}{\partial x}}_{\text {Dispersão }} d x+\underbrace{V \frac{d C}{d t}}_{\text {Advecção }}+\underbrace{S}_{\text {Reações Cinéticas }}
$$

Em que: $M$ é a massa do constituinte, $V$ é o volume, $t$ é o tempo, $x$ é a distância, $C$ é a concentração do constituinte, $A_{x}$ é a área da seção transversal de cada elemento computacional, $D_{L}$ é coeficiente de dispersão longitudinal, $U$ é a velocidade média de escoamento e $S$ refere-se às fontes externas (entradas ou retiradas) [5].

Inicialmente serão escolhidas as variáveis linguísticas, levando em consideração as que mais interferem na qualidade da água. Para cada variável linguística serão utilizados cinco termos linguísticos (PÉSSIMO, RUIM, REGULAR, BOM e EXCELENTE) e escolhidas funções de pertinência triangulares e trapezoidais. Serão utilizados o método de Mandami para inferência e o método da centroide para defuzificação. A defuzificação, por meio do método centroide, retorna um valor algébrico correspondente aos valores difusos encontrados após a etapa de inferência [7]. Por fim serão criadas tabelas com a base de regras do sistema e o índice final de qualidade da água do rio Cachoeira (IQARC). Com base no conhecimento de especialistas e literatura consultada, serão determinadas a faixa aceitável de cada substância nas águas do rio Cachoeira.

As simulações serão realizadas nos computadores do Núcleo de Biologia Computacional e Gestão de Informações Biológicas (NBCGIB) da Universidade Estadual de Santa Cruz (UESC), utilizando o software Matlab. Após as simulações, serão comparados os resultados obtidos no modelo QUAL2K e no modelo fuzzy proposto a luz dos padrões de potabilidade da água fixados pelo Ministério da Saúde e resolução CONAMA 357/2005.

Palavras-chave: Rio Cachoeira, Lógica Fuzzy, Qualidade da água

\section{Referências}

[1] F. C. F. de Paula; D. M. L. Silva; C. M. Souza, Tipologias Hidroquímicas das Bacias Hidrográficas do Leste da Bahia, Revista Virtual de Química, 4(2012) 365-373.

[2] A. Lermontov; L. Yokoyama; M. Lermontov; M. A. S. Machado, Aplicação da lógica nebulosa na parametrização de um novo índice de qualidade das águas, Engevista, 10 (2008) 106-125.

[3] M. Z. T. P. Q. L. Lucio; S. S. dos Santos; D. M. L. da Silva, Hydrochemistry of Cachoeira River (Bahia State, Brazil), Acta Limnologica Brasiliensia, 24(2012) 181-192.

[4] F. V. E. C. Oliveira, O que viu o rio: Reportagem sobre a Relação entre o Rio Cachoeira e a Cidade de Itabuna (BA),Universidade Federal de Viçosa, 2013, 34p.

[5] L. F. Oppa, "Utilização de Modelo Matemático de Qualidade da Água para Análise de Alternativas de Enquadramento do Rio Vacaí Mirim”, Dissertação de Mestrado, PPGEC-UFSM, 2007.

[6] A. G. Pinho, "Estudo da Qualidade das Águas do Rio Cachoeira - Região Sul da Bahia”, Dissertação de Mestrado, PRODEMA-UESC, 2001.

[7] C. F. A. Pires; E. T. Oliveira; F. B. S. Oliveira; F. F. Lopes, Desenvolvimento de uma Ferramenta para Análise da Qualidade da Água do Rio Cachoeira Utilizando Lógica Fuzzy, Anais do XVI Encontro de Modelagem Computacional/IV Encontro de Ciência e Tecnologia de Materiais/III Encontro Regional de Matemática Aplicada e Computacional, UESC, 2013. 